\title{
Educational value assessment of YouTube surgical videos of tension-free vaginal tape obturator (TVT-O) and trans-obturator vaginal tape (TOT)
}

\author{
Yuan-Zhuo Chen", Liao Peng", Bo-Ya Li, Jia-Wei Chen, Shuang Chen, De-Yi Luo^ \\ Department of Urology, Institute of Urology, West China Hospital, Sichuan University, Chengdu, China \\ Contributions: (I) Conception and design: YZ Chen, L Peng; (II) Administrative support: DY Luo; (III) Provision of study materials or patients: YZ \\ Chen, BY Li; (IV) Collection and assembly of data: YZ Chen, BY Li; (V) Data analysis and interpretation: YZ Chen, S Chen, BY Li; (VI) Manuscript \\ writing: All authors; (VII) Final approval of manuscript: All authors. \\ "These authors contributed equally to this work. \\ Correspondence to: De-Yi Luo, MD, PhD. Department of Urology, Institute of Urology, West China Hospital, Sichuan University; No. 37 Guo Xue \\ Xiang, Chengdu 610041, China. Email: luodeyi1985@163.com.
}

\begin{abstract}
Background: YouTube, as a widely used video website around the world, contains a large number of surgical teaching videos, providing a good platform for doctors to learn surgery, but its content and quality are uneven. Tension-free vaginal tape obturator (TVT-O) and trans-obturator vaginal tape (TOT) are common surgical methods for the treatment of stress urinary incontinence (SUI), and there are many videos on YouTube teaching these procedures. We aimed to assess the educational value of surgical videos of TVT-O and TOT on YouTube.

Methods: A comprehensive search was conducted for "tension-free vaginal tape obturator" and "transobturator vaginal tape" on YouTube on August 22. After referring to LAParoscopic surgery Video Educational GuidelineS (LAP-VEGaS) and previous studies, we developed a checklist containing 5 major items and 18 minor items. SPSS 26 was applied to data and correlation analysis.

Results: A total of 36 videos were assessed. The average number of days available was 1,956.6 days (range, 190-4,152 days) and the average length was $9.7 \mathrm{~min}$ (range, 1.8-73.6 $\mathrm{min}$, SD: 13.65). Video definition is divided into high, moderate and low, accounting for $22 \%, 36 \%$ and $42 \%$ respectively. The average score of the included videos was 7.39 (range, 3-16, SD: 3.57). The correlation analysis indicated that the video quality score has a certain correlation with the length of the video, but has no significant correlation with other factors and there was no significant correlation between audience likes and other factors.

Conclusions: On YouTube, we still lack high educational value videos about TVT-O and TOT, and the existing videos are deficient in the explanation of critical steps, the key points of patients' perioperative management, and the application of auxiliary teaching tools. This further indicates the importance of improving educational videos of surgery, and an authoritative checklist for urologic surgery.
\end{abstract}

Keywords: Tension-free vaginal tape obturator (TVT-O); trans-obturator vaginal tape (TOT); YouTube; quality assessment; surgical education

Submitted Sep 14, 2021. Accepted for publication Dec 24, 2021.

doi: $10.21037 /$ tau-21-814

View this article at: https://dx.doi.org/10.21037/tau-21-814

^ ORCID: 0000-0002-9436-036X. 


\section{Introduction}

Stress urinary incontinence (SUI) is a common disease in women. It refers to the complaint of involuntary urine leakage with effort, exertion, sneezing, or coughing (1). SUI seriously affects the quality of life and social activities of female patients. Among Chinese adult females, the incidence of SUI is as high as $18.9 \%$, especially $28 \%$ in the 50-59 age group (2). In surgical treatment, mid-urethral sling operations have been proved to be an effective means for the treatment of SUI, with definite long-term efficacy and safety. In addition to traditional tension-free vaginal tape (TVT), tension-free vaginal tape obturator (TVT-O) and trans-obturator vaginal tape (TOT) are also widely used and have good therapeutic effects (3).

In the past, field instruction and clinical observation were the most important methods of surgical teaching. With the use of multimedia and the development of video recording equipment, surgical video has become an essential part of surgical education resources $(4,5)$. YouTube, the popular video site, provides a platform for surgeons to share videos of their operations, regarded as the most frequently used educational video source for surgical preparation (6). Many people can learn and improve their own surgical abilities through videos posted by other doctors. However, due to the lack of professional peer review and quality evaluation system, the quality of surgical videos available on YouTube is irregular, which is not only a waste of time to find good resources, but some low-quality surgical videos may be the wrong example. Therefore, after the release of LAPVEGaS practice guidelines reporting of educational videos in laparoscopic surgery (7), many scholars began to evaluate the quality of related surgery videos.

TVT-O and TOT surgery play an important role in the field of incontinence surgery (8-10). On YouTube, there are dozens of educational videos about these two procedures. This study aims to assess the educational value of surgical videos of TVT-O and TOT on YouTube. Moreover, to provide convenience for trainees and to provide a reference for educational video producers.

\section{Methods}

Two authors conducted a comprehensive search for "tension-free vaginal tape obturator", "trans-obturator vaginal tape", "TVT-O" and "TOT" on YouTube individually on August 22, 2021, then sorted and screened the videos according to the following inclusion and exclusion criteria. If the videos that met the inclusion and exclusion criteria were found in places other than the search results, such as similar videos recommended by YouTube, simplifying keywords and expanding the search scope would be carried out. Videos were included if they met these criteria: (I) the title or video should describe the procedure; (II) videos recorded complete main steps, not a partial segment; (III) videos were annotated with audio or text. Beyond that, other videos were excluded, such as commercial advertisements and promotional videos. During the process, if there were any disagreements or doubts between the two authors, a joint decision would be made with the help of the third author.

Due to the lack of a standard and authoritative urological surgery video quality evaluation checklist, we drew on the LAParoscopic surgery Video Educational GuidelineS (LAP-VEGaS) practice guidelines (7) and similar research scale of thulium laser enucleation of the prostate (11) to develop the final checklist, which was shown in Table 1. The checklist was developed by all authors, with the assistance of two experienced urogynecologists with over 700 incontinence surgery and at least 200 cases of TVT-O or TOT surgery experience, containing 5 major items (including author's information and video introduction, case presentation, demonstration of the surgical procedure, outcomes of procedure, and associated educational content) and 18 minor items. The overall content was consistent with previously published scales, with adjustments for surgical procedures and outcome measures. For the standard procedure of TVT-O and TOT surgery, we referred to the published techniques by de Leval (12) and Delorme (13). Each sub-item counts for one point out of a total of 18 . The higher the score, the higher the educational quality.

We collected the data of the videos included in the evaluation scope and recorded the baseline data, including days online, region, length, video definition (we regarded $1,080 \mathrm{P}$ as high, $720-480 \mathrm{P}$ as moderate and $360-240 \mathrm{P}$ as low video definition), number of likes and dislikes. Data collection and video evaluation were done by two authors separately (the video reviewers were both urogynaecology doctors who had watched and studied at least 20 TVT-O or TOT operations). Before video evaluation, they all learned standard surgical procedures referring to published techniques by de Leval (12) and Delorme (13). If the total scores difference of a video were more than 3 points, the third author would score the video and take the average score. The collation and proofreading of the data were done jointly by these three authors and supervised by all the 
Table 1 The checklist for the evaluation of TVT-O and TOT surgical videos' educational value

\begin{tabular}{|c|c|c|}
\hline Items of checklist & $\mathrm{N}$ & $\%$ \\
\hline \multicolumn{3}{|l|}{ Author's information and video introduction } \\
\hline Authors' information & 23 & 63.9 \\
\hline The title of the video including the procedure & 32 & 88.9 \\
\hline Conflict of interest disclosure & 0 & 0 \\
\hline Patient anonymity and privacy protection & 36 & 100 \\
\hline Baseline patient characteristics & 3 & 8.3 \\
\hline Preoperative work-up and treatments & 6 & 16.6 \\
\hline The degree of stress urinary incontinence before surgery & 2 & 5.6 \\
\hline Anatomic demonstration & 23 & 63.9 \\
\hline Standardized procedures for surgery step by step & 34 & 94.4 \\
\hline Detailed explanation of critical steps & 19 & 52.7 \\
\hline Cystoscopy was performed during the operation & 4 & 11.1 \\
\hline \multicolumn{3}{|l|}{ Outcomes of procedure } \\
\hline The operating time & 2 & 5.6 \\
\hline The length of hospitalization & 4 & 11.1 \\
\hline The morbidity of intraoperative and postoperative complications & 10 & 27.7 \\
\hline
\end{tabular}

TVT-O, tension-free vaginal tape obturator; TOT, trans-obturator vaginal tape.

other authors.

The study was conducted in accordance with the Declaration of Helsinki (as revised in 2013).

\section{Statistical analysis}

Data analysis was performed with SPSS Statistics (Version 26 for Windows, IBM Corporation). The mean, ranges, and standard deviation (SD) were recorded as the primary outcome measure. Pearson's correlation coefficient was applied to evaluate the correlations among variables. Correlation is significant at the $\mathrm{P}<0.05$ level.

\section{Results}

A total of 145 videos were retrieved. After screening by inclusion and exclusion criteria, 36 videos entered the final list, and the video inclusion process was shown in Figure 1. The baseline data were recorded in Table 2 .

From our primary outcome measure, the average score of the included videos was 7.39 (range, 3-16, SD: 3.57). The video with the highest score of 16, titled Transobturator Tape Operation (TOT), was created by Dr. Mehmet Akyuz from France in 2019. Most videos can be performed in a standard surgical procedure (94.4\%) with clear indications of how 


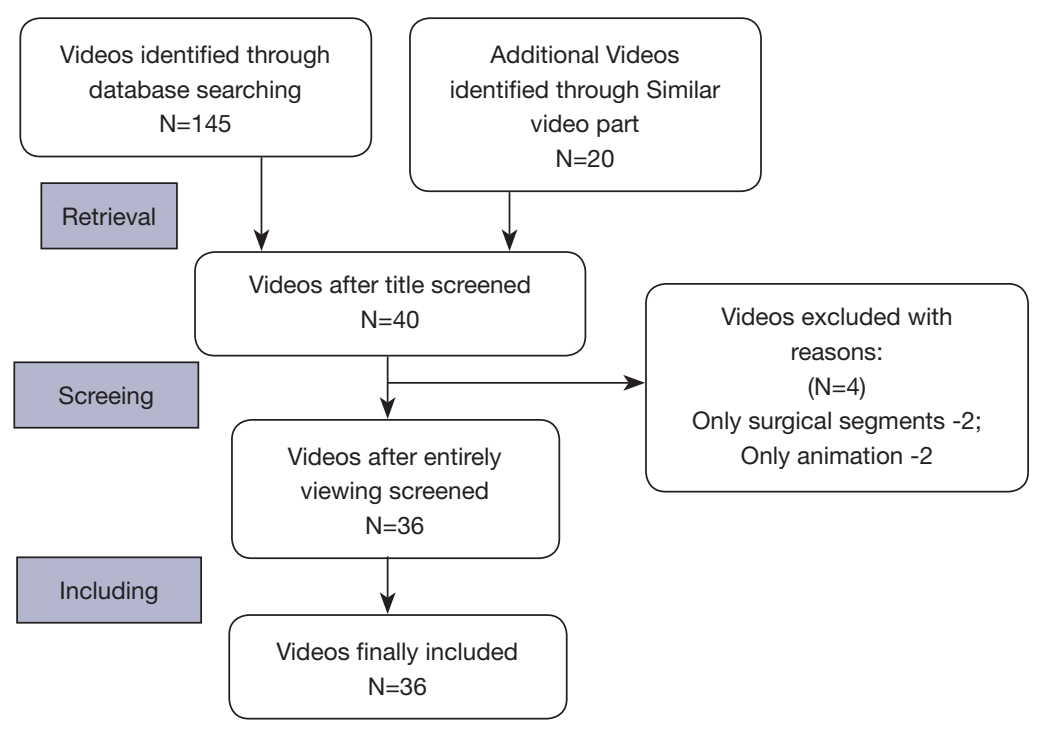

Figure 1 Flowchart of video inclusion.

the procedure is performed $(88.9 \%)$, protecting patient privacy $(100 \%)$. However, as educational videos, only a few videos cover associated educational content $(41.7 \%)$ and outcomes of procedure (27.7\%).

The average number of days available for existing educational videos (as of August 22, 2021) was 1,956.6 days (range, 190-4,152 days, normal distribution, median: $1,846.5)$, with the earliest videos dating back to 2010 . Among these included videos, the average length was 9.7 min (range, 1.8-73.6 min, SD: 13.65). Although the shortest video was composed of fragments of each step, the key surgical steps were complete, and there were figures to assist teaching, which could be used as learning materials for surgical beginners. The majority of videos originate from India (33\%), except for those without a clear country of authorship, and the country distribution of videos is shown in Figure S1. Video definition is divided into high, moderate and low, accounting for $22 \%, 36 \%$ and $42 \%$ respectively. The average number of likes was 98.8 (SD: 177.5) and the average number of dislikes was 21.8 (SD: 62).

Although the correlation analysis indicated that the video quality score had a negative correlation with the length of the video $(\mathrm{r}=-0.37, \mathrm{P}<0.05)$, the correlation was not strongly significant. Moreover, video quality score had no significant correlation with the number of likes and dislikes, and the number of days of release, meanwhile there was no significant correlation between audience likes and other factors. The results of correlation analysis are performed in Table 3.

\section{Discussion}

This study evaluates the quality of videos by searching YouTube for educational videos of TVT-O and TOT, with the aim of identifying videos that have pedagogical value, as well as figuring out the shortcomings of existing instructional videos and providing a reference for more and better-quality videos in the future. To our knowledge, this is the first research to evaluate the quality of TVT-O and TOT educational videos on YouTube, as well as the first to use our modified checklist to evaluate the video quality of these surgical procedures.

With the increasing use of multimedia, people have more and more ways to obtain information. After the release of the laparoscopic checklist (7), some scholars have carried out some studies on video quality evaluation of abdominal surgery, providing a reference for surgical beginners (11,14-16). Unfortunately, many studies have shown that the included videos are generally not rated high, with incomplete content and little teaching significance, failing to meet the standards of a good surgical teaching video. YouTube, as a video-sharing website facing the public, lacks a professional video review and quality assessment system, which leads to the uneven quality of uploaded surgical videos, and further demonstrates the importance of video quality assessment.

In the preparation stage of the study, we found that the formulation of the checklist was the most important part of the video quality assessment. Previous articles related to 
Table 2 Characteristic of included 36 surgical videos of TVT-O and TOT on YouTube

\begin{tabular}{|c|c|c|c|c|c|c|c|c|}
\hline No. title & $\begin{array}{c}\text { Date of } \\
\text { uploaded }\end{array}$ & $\begin{array}{l}\text { Days } \\
\text { online }\end{array}$ & Region & $\begin{array}{l}\text { Length, } \\
\text { min }\end{array}$ & Video definition & Like & Dislike & Score \\
\hline $\begin{array}{l}\text { 1. TVT-O Continence Surgery for Stress Urinary } \\
\text { Incontinence (Dr. RK Mishra) } 2017\end{array}$ & $2017 / 9 / 8$ & 1,444 & India & 3.86 & High $1,080 \mathrm{P}$ & 300 & 36 & 7 \\
\hline $\begin{array}{l}\text { 2. Transobturator Sling | Stress Urinary Incontinence } \\
\text { | urine leakage repair | TVT-O (Dr. Doughlas Miyazaki } \\
\text { 2020) }\end{array}$ & $2020 / 12 / 5$ & 260 & USA & 4.73 & High $1,080 \mathrm{P}$ & 6 & 0 & 11 \\
\hline $\begin{array}{l}\text { 4. TVT-O procedure for stress urinary incontinence (Dr. } \\
\text { Engelbert Hanzal) } 2011\end{array}$ & $2011 / 7 / 24$ & 3,682 & Austria & 4.25 & Moderate 480P & 77 & 25 & 6 \\
\hline $\begin{array}{l}\text { 5. Tension Free Transvaginal Tape TVT and TVTO and } \\
\text { TOT (Dr. RK Mishra) } 2015\end{array}$ & $2015 / 8 / 2$ & 2,212 & India & 50.28 & High 1,080P & 163 & 17 & 13 \\
\hline $\begin{array}{l}\text { 7. TVT O for the Treatment of Female Stress Urinary } \\
\text { Incontinence (unknown doctor) } 2013\end{array}$ & $2013 / 9 / 21$ & 2,892 & Unknown & 10.18 & Low 360P & 39 & 10 & 3 \\
\hline $\begin{array}{l}\text { 8. Transobturator transfixation (TOT) for Stress urinary } \\
\text { incontinence (Dr. Varun H. Shah) } 2017\end{array}$ & $2017 / 9 / 21$ & 1,431 & India & 13.06 & Moderate 720P & 19 & 2 & 6 \\
\hline $\begin{array}{l}\text { 9. Transobturator Tape for female Stress Incontinence } \\
\text { (Dr. Javier) } 2013\end{array}$ & $2013 / 11 / 9$ & 2,843 & Spain & 3.25 & Moderate 720P & 0 & 0 & 5 \\
\hline $\begin{array}{l}\text { 10. Azayem Procedures - Trans Obturator Tape (T.O.T) } \\
\text { for management of Stress Urinary Incontinence (Dr. } \\
\text { Khaled Abuelazayem) } 2012\end{array}$ & $2012 / 6 / 6$ & 3,364 & UAE & 6.43 & Moderate 720P & 92 & 66 & 10 \\
\hline $\begin{array}{l}\text { 15. Trans Obturator Tape (TOT) placement for Stress } \\
\text { Urinary Incontinence in Female (Dr. R.B.NERLI) } 2019\end{array}$ & $2019 / 10 / 6$ & 686 & India & 3.36 & Moderate 720P & 5 & 0 & 10 \\
\hline $\begin{array}{l}\text { 16. Trans Obturator Tape (TOT) insertion for SUI (Dr. } \\
\text { Shridhar Dayama) } 2021\end{array}$ & $2021 / 2 / 5$ & 198 & India & 4.35 & High $1,080 \mathrm{P}$ & 12 & 0 & 11 \\
\hline $\begin{array}{l}\text { 17. Stress Urinary Incontinence - TOT surgery } \\
\text { (Dr. Oleg Hublarov) } 2013\end{array}$ & $2013 / 10 / 12$ & 2,871 & Latvia & 19.50 & Low 360P & 103 & 53 & 3 \\
\hline $\begin{array}{l}\text { 18. Technique of TOT placement (Dr. Divakar Dalela) } \\
2018\end{array}$ & $2018 / 3 / 23$ & 1,248 & India & 11.92 & Low 240P & 536 & 16 & 10 \\
\hline 19. TOT - TRANSOBTURATOR TAPE (Dr. Bulent) 2015 & $2015 / 3 / 7$ & 2,360 & Turkey & 2.20 & Low 360P & 9 & 4 & 9 \\
\hline $\begin{array}{l}\text { 20. Transobturator Tape Operation (TOT) } \\
\text { (Dr. Mehmet Akyuz) } 2019\end{array}$ & $2019 / 3 / 21$ & 885 & France & 9.55 & High $1,080 \mathrm{P}$ & 57 & 2 & 16 \\
\hline 21. TVT Obturator (Dr. Shota Natsvlishvili) 2010 & $2010 / 4 / 10$ & 4,152 & Unknown & 6.06 & Low 360P & 40 & 4 & 3 \\
\hline
\end{tabular}

Table 2 (continued) 
Table 2 (continued)

\begin{tabular}{|c|c|c|c|c|c|c|c|c|}
\hline No. title & $\begin{array}{c}\text { Date of } \\
\text { uploaded }\end{array}$ & $\begin{array}{l}\text { Days } \\
\text { online }\end{array}$ & Region & $\begin{array}{l}\text { Length, } \\
\min \end{array}$ & Video definition & Like & Dislike & Score \\
\hline $\begin{array}{l}\text { 22. Trans-Obturator technique using ARIS } \\
\text { (unknown doctor) } 2018\end{array}$ & $2018 / 11 / 22$ & 1,004 & Chile & 5.75 & Moderate 480P & 10 & 0 & 3 \\
\hline 23. TOT for SUI (Dr. Ajit Tidame) 2018 & $2018 / 2 / 23$ & 1,276 & India & 7.80 & Low 360P & 6 & 0 & 4 \\
\hline $\begin{array}{l}\text { 24. DynaMesh }{ }^{\circledR} \text {-SIS direct - OR-Video: Transobturator } \\
\text { Sling - TOT (out/in) (Dr. Richter) } 2019\end{array}$ & $2019 / 2 / 19$ & 915 & Germany & 3.23 & Moderate 480P & 0 & 0 & 7 \\
\hline 25. TVTO (Dr. Mauro Gatti) 2013 & $2013 / 5 / 1$ & 3,035 & Unknown & 5.23 & Low 240P & 121 & 30 & 3 \\
\hline $\begin{array}{l}\text { 26. TOT for stress urinary incontinence (unknown } \\
\text { doctor) } 2015\end{array}$ & $2015 / 9 / 5$ & 2,178 & Unknown & 4.58 & Low 360P & 20 & 4 & 3 \\
\hline $\begin{array}{l}\text { 27. Stress urinary incontinence TOT sling (Dr. Shekhar } \\
\text { Amale) } 2020\end{array}$ & $2020 / 3 / 20$ & 520 & India & 7.57 & Moderate 480P & 4 & 0 & 8 \\
\hline 29. Modified TVT-O (Dr. Avinash Odugoudar) 2017 & $2017 / 8 / 31$ & 1,452 & Unknown & 4.96 & Moderate 480P & 0 & 0 & 11 \\
\hline $\begin{array}{l}\text { 30. Step by Step Guide to Trans-Obturator Tape (TOT) } \\
\text { Repair for SUI (Stress Urine Incontinence) } \\
\text { (Dr. Jay Mehta) } 2019\end{array}$ & $2019 / 11 / 10$ & 651 & India & 10.60 & Low 360P & 198 & 23 & 9 \\
\hline $\begin{array}{l}\text { 31. Transobturator urethral suspension mini invasive } \\
\text { procedure stress urinary incontinence } \\
\text { (unknown doctor) } 2013\end{array}$ & $2013 / 9 / 21$ & 2,892 & Unknown & 5.00 & Low 240P & 77 & 27 & 7 \\
\hline 32. TOT-sling (Dr. Sam Siddighi) 2017 & $2017 / 6 / 29$ & 1,515 & Unknown & 4.37 & Low 360P & 107 & 33 & 9 \\
\hline 36. TVT-O Abbrevo (Dr. Ciro Sommella) 2014 & 2014/10/14 & 2,504 & Unknown & 4.57 & Low $360 P$ & 857 & 370 & 7 \\
\hline
\end{tabular}

TVT-O, tension-free vaginal tape obturator; TOT, trans-obturator vaginal tape.

Table 3 Correlation analysis for impacting the scores

\begin{tabular}{lcccc}
\hline Factors & 1 & 2 & 3 & 4 \\
\hline Scores & 1 & & & \\
Days online & -0.322 & 1 & & \\
Video length & $-0.370^{\star}$ & -0.064 & 0.244 & 1 \\
Likes & 0.189 & 0.042 & -0.037 & $0.797^{\star *}$ \\
Dislikes & -0.006 & 0.166 & 1 \\
\hline
\end{tabular}

*, correlation is significant at the 0.05 level (2 tailed); ${ }^{* \star}$, correlation is significant at the 0.01 level (2 tailed). 
laparoscopic surgery have checklist guidelines, but there is a temporary lack of relevant guidelines for TVT-O and TOT surgery, which poses a challenge for our study. After referring to the previous scale and with the help of two experienced gynecologists and urologists, we jointly developed this checklist to evaluate the video quality of this kind of surgery comprehensively.

Most of the videos still fall short of the requirements for a good surgical teaching video, with only half explaining critical steps in detail and only $11.1 \%$ showing cystoscopic results. In the correlation analysis, video scores were not significantly associated with many factors, only with video length, which is in accordance with previous studies' results. The positive correlation with video length maybe because the longer the video, the richer and more comprehensive the content, the higher the score.

There are still many unavoidable limitations in this study. Firstly, the retrieval scope of our videos is only limited to YouTube, and more websites should be included to obtain the videos. However, as a well-known video-sharing platform, YouTube has a low registration threshold and a large number of audiences worldwide, so we hope that more high educational value videos can be published on YouTube to help trainees. The English audio commentary level of the videos was uneven, which made it difficult for us to judge whether the key surgical steps were accurately described, and affected the assessment to some extent. Besides, due to the lack of relevant statistical processing technology, we were unable to analyze the video comments. Owing to the lack of professional comments and mature supervision system, it is difficult for readers to benefit from comments. It is hoped that relevant studies can be carried out in subsequent studies. Finally, there is a lack of video quality evaluation criteria recommended by the guidelines. Although we have produced the checklist according to specific surgical methods, more expert advice is still needed to jointly develop an authoritative checklist.

\section{Conclusions}

On YouTube, we still lack high educational value videos about TVT-O and TOT, and the existing videos are deficient in the explanation of critical steps, the key points of patients' perioperative management, and the application of auxiliary teaching tools (such as drawings, tables, 3D animations, accompanying subtitles and audio explanations). This further indicates the importance of improving educational videos of surgery, and an authoritative checklist for urologic surgery.

\section{Acknowledgments}

Funding: This study was funded by the National Natural Science Fund of China (No. 81770673) and 1.3.5 Project for Disciplines of Excellence, West China Hospital, Sichuan University (No. ZY2017310).

\section{Footnote}

Conflicts of Interest: All authors have completed the ICMJE uniform disclosure form (available at https://tau.amegroups. com/article/view/10.21037/tau-21-814/coif). The authors have no conflicts of interest to declare.

Ethical Statement: The authors are accountable for all aspects of the work in ensuring that questions related to the accuracy or integrity of any part of the work are appropriately investigated and resolved. The study was conducted in accordance with the Declaration of Helsinki (as revised in 2013).

Open Access Statement: This is an Open Access article distributed in accordance with the Creative Commons Attribution-NonCommercial-NoDerivs 4.0 International License (CC BY-NC-ND 4.0), which permits the noncommercial replication and distribution of the article with the strict proviso that no changes or edits are made and the original work is properly cited (including links to both the formal publication through the relevant DOI and the license). See: https://creativecommons.org/licenses/by-nc-nd/4.0/.

\section{References}

1. Haylen BT, de Ridder D, Freeman RM, et al. An International Urogynecological Association (IUGA)/ International Continence Society (ICS) joint report on the terminology for female pelvic floor dysfunction. Neurourol Urodyn 2010;29:4-20.

2. Zhang L, Zhu L, Xu T, et al. A Population-based Survey of the Prevalence, Potential Risk Factors, and Symptomspecific Bother of Lower Urinary Tract Symptoms in Adult Chinese Women. Eur Urol 2015;68:97-112.

3. Ford AA, Rogerson L, Cody JD, et al. Mid-urethral sling operations for stress urinary incontinence in women. Cochrane Database Syst Rev 2017;7:CD006375.

4. Glass NE, Kulaylat AN, Zheng F, et al. A national survey 
of educational resources utilized by the Resident and Associate Society of the American College of Surgeons membership. Am J Surg 2015;209:59-64.

5. Pugh CM, Watson A, Bell RH Jr, et al. Surgical education in the internet era. J Surg Res 2009;156:177-82.

6. Rapp AK, Healy MG, Charlton ME, et al. YouTube is the Most Frequently Used Educational Video Source for Surgical Preparation. J Surg Educ 2016;73:1072-6.

7. Celentano V, Smart N, McGrath J, et al. LAP-VEGaS Practice Guidelines for Reporting of Educational Videos in Laparoscopic Surgery: A Joint Trainers and Trainees Consensus Statement. Ann Surg 2018;268:920-6.

8. Serati M, Braga A, Caccia G, et al. TVT-O for treatment of pure urodynamic stress urinary incontinence: Efficacy and adverse effects at 13-years follow-up. Neurourol Urodyn 2020;39:1423-9.

9. Tammaa A, Aigmüller T, Hanzal E, et al. Retropubic versus transobturator tension-free vaginal tape (TVT vs TVT-O): Five-year results of the Austrian randomized trial. Neurourol Urodyn 2018;37:331-8.

10. Thomas T. TVT-O for SUI. Nat Rev Urol 2020;17:370.

11. Yang K, Meng Y, Zhang K. Educational value of You'Tube

Cite this article as: Chen YZ, Peng L, Li BY, Chen JW, Chen S, Luo DY. Educational value assessment of YouTube surgical videos of tension-free vaginal tape obturator (TVT-O) and trans-obturator vaginal tape (TOT). Transl Androl Urol 2022;11(1):1-8. doi: 10.21037/tau-21-814
Surgical Videos of Thulium Laser Enucleation of The Prostate (ThuLEP): the quality assessment. Transl Androl Urol 2021;10:2848-56.

12. de Leval J, Waltregny D. New surgical technique for treatment of stress urinary incontinence TVT-Obturator: new developments and results. Surg Technol Int 2005;14:212-21.

13. Delorme E, Droupy S, de Tayrac R, et al. Transobturator tape (Uratape): a new minimally-invasive procedure to treat female urinary incontinence. Eur Urol 2004;45:203-7.

14. Chapman D, Weaver A, Sheikh L, et al. Evaluation of Online Videos of Laparoscopic Sleeve Gastrectomy Using the LAP-VEGaS Guidelines. Obes Surg 2021;31:111-6.

15. Rajan D, Pillai VG, Varghese P. Educational Utility of Social Media for Laparoscopic Surgery in India: A CrossSectional Survey of Popular Indian Communities on Facebook. Adv Med Educ Pract 2021;12:491-8.

16. Zwerus EL, Molenaars RJ, van den Bekerom MPJ, et al. Accuracy and Quality of Educational Videos for Elbow Physical Examination: A Search from the Earliest Year until October 2018. Arch Bone Jt Surg 2021;9:93-101. 


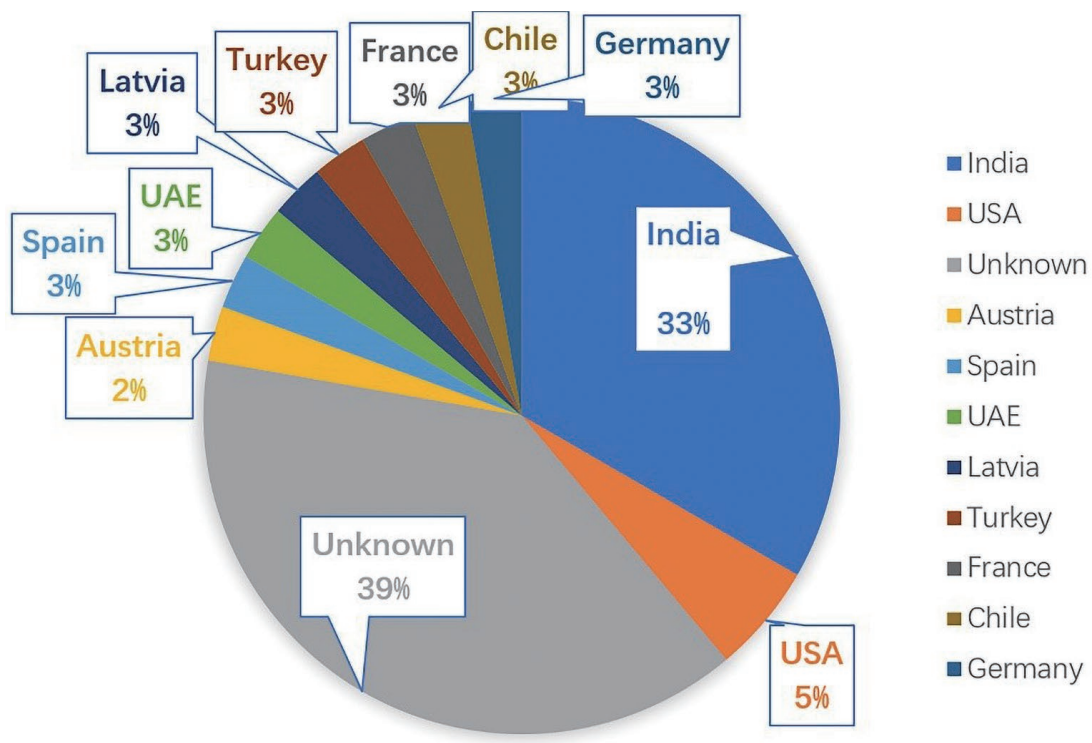

Figure S1 The distribution of the authors' countries. 